\title{
Analisis Semiotika Representasi Ibu Tunggal dalam Film Susah Sinyal
}

\author{
Millenia Vega Wong, Daniel Tamburian \\ vegamillenia@gmail.com,danielt@fikom.untar.ac.id \\ Fakultas Ilmu Komunikasi Universitas Tarumanagara
}

\begin{abstract}
Film is a description of audio visual media in mass communication that can display words, sounds, stories and their combination. Films are a means of public entertainment in which there are insights, knowledge and messages to be conveyed to the audience. Susah Sinyal is a film that tells the story of a single parent woman in carrying out her role. The role of a single parent is a situation where a single parent must play the role of both mother and father at the same time. This research focuses on the role of a single mother named Ellen who is represented in the Susah Sinyal film. Ellen's really love her job and it makes her lose time with her child so that the relationship between the two doesn't get along. Therefore, this study aims to show how the representation of single mothers in the Susah Sinyal film. This type of research uses qualitative research and Roland Barthes' semiotic analysis method. Researchers collected data through observation and observation by watching the film Susah Tanda. Through observation, the researcher identified a number of scenes that represented single mothers in the Susah Sinyal film. The results of this study indicate that single mothers represented by Ellen have a firm and emotional character. In addition, Ellen is also an independent woman, hardworking, very responsible for what she does, and optimistic about her abilities.
\end{abstract}

Keywords: film, representation, semiotics, single mother

\begin{abstract}
Abstrak
Film adalah suatu gambaran media audio visual dalam komunikasi massa yang dapat menampilkan kata-kata, suara, cerita dan gabungannya. Film merupakan sarana hiburan masyarakat yang didalamnya terdapat wawasan, pengetahuan dan pesan yang ingin disampaikan kepada penikmatnya. Film Susah Sinyal merupakan film yang bercerita tentang kehidupan perempuan single parent dalam menjalankan perannya. Peran single parent merupakan keadaan di mana orang tua tunggal yang harus memerankan perannya sebagai ibu maupun ayah sekaligus. Penelitian ini berpusat pada peran ibu tunggal bernama Ellen yang direpresentasikan dalam film Susah Sinyal. Kecintaan Ellen dengan pekerjaannya membuat ia kehilangan waktu dengan anaknya sehingga membuat hubungan keduanya tidak akur. Maka dari itu, penelitian ini bertujuan untuk menunjukkan bagaimana representasi ibu tunggal dalam film Susah Sinyal. Jenis penelitian ini menggunakan penelitian kualitatif dan metode analisis semiotika Roland Barthes. Peneliti mengumpulkan data melalui observasi dan pengamatan dengan menonton film Susah Sinyal. Melalui pengamatan, peneliti mengidentifikasi sejumlah scene yang merepresentasikan ibu tunggal dalam film Susah Sinyal. Hasil penelitian ini menunjukkan ibu tunggal yang direpresentasikan oleh Ellen mempunyai karakter yang tegas dan emosional. Selain itu, Ellen juga adalah perempuan yang mandiri, pekerja keras, sangat bertanggung jawab dengan apa yang dikerjakannya, dan optimis dengan kemampuannya.
\end{abstract}

Kata kunci: film, ibu tunggal, representasi, semiotika 


\section{Pendahuluan}

Keluarga adalah bagian terkecil dari masyarakat, yang terdiri dari laki-laki dan perempuan yang disatukan oleh ikatan pernikahan dengan meninjau hal-hal yang akhirnya menjadi suatu kelengkapan yang lengkap dan memiliki keturunan yang akan menjadi bagian masyarakat. Akan tetapi, walaupun telah disatukan dalam ikatan pernikahan, terkadang pernikahan gagal dan kandas. Hal inilah yang mengakibatkan keluarga menjadi tidak lengkap dan terjadi perceraian. Salah satu akibat dari perceraian adalah adanya single mother (Dewi, 2017:44).

Badan Pusat Statistik 2013 menyatakan bahwa di Indonesia, jumlah single mother lebih banyak dari pada single father. Hal ini terbukti dari persentase ibu tunggal sebesar $14,84 \%$ dan jauh lebih besar dari persentase ayah tunggal yang hanya 4,05\% (Rahayu, 2017:85).

Perceraian tidak hanya mengubah struktur dalam sebuah keluarga tetapi inti sari dari interaksi dan hubungannya. Para ibu mendapati perubahan perhatian terhadap pengalaman keseharian anak remaja mereka serta manajemen dan rutinitas rumah tangga yang tidak dapat di prediksi sebelum terjadinya perceraian. Hal ini memicu terjadinya ketimpangan pada remaja yang disebabkan ketidakutuhan orang tua dalam sebuah keluarga yang berakibat terhadap pertumbuhan konsep diri anak. Fitzpatrick dan Ritchie (Vangelisti, dalam Asdir, 2004: 183) mengemukakan komunikasi keluarga, menjelaskan mengenai komunikasi yang mengarah pada orientasi percakapan (conversation orientation) dan orientasi persetujuan (conformity orientation) yang menaruh pada komunikasi keluarga (Asdir, 2015).

Salah satu Film Indonesia yang membahas mengenai representasi ibu tunggal adalah Film Susah Sinyal. Film Susah Sinyal yang bergenre drama komedi ini disutradarai oleh Ernest Prakasa yang tayang di bioskop pada 28 Desember 2017. Dalam pembuatan naskah, Ernest Prakasa dibantu oleh sang istri, Meira Anastasia. Film yang meraih 2.172.512 penonton ini mengisahkan tentang seorang single mother yang berjuang menjalani kehidupan serta menceritakan pentingnya kedekatan ibu dengan anak.

Menurut Muhammad Faisal Wisnu Ananta Putra, dalam film ini Ellen direpresentasikan sebagai single mother yang pekerja keras, cekatan, dan mandiri dalam menghidupi keluarganya. Tetapi di satu sisi, dia tidak memberikan perannya sebagai ibu yang harus mengasuh dan mendidik anak (Kiara). Alhasil, Kiara merasa kurang perhatian dan dukungan dari ibunya yang seharusnya ia dapatkan. Dari situlah, Kiara menjadi anak yang pemberontak dan selalu melampiaskan amarahnya di media sosial. Hubungan Kiara dan Ellen yang tidak harmonis menunjukkan kurangnya komunikasi, kehadiran, waktu, cinta dan kasih saying seorang ibu terhadap anaknya (Putra, 2019:3).

Penulis tertarik melakukan penelitian tentang "Analisis Semiotika Representasi Ibu Tunggal dalam Film Susah Sinyal" karena peneliti ingin mengetahui bagaimana representasi ibu tunggal dalam film Susah Sinyal. Rumusan masalah penelitian ini adalah bagaimana representasi ibu tunggal dalam film Susah Sinyal. Tujuan penelitian ini adalah untuk mengetahui representasi Ibu Tunggal dalam film Susah Sinyal dan untuk mengetahui simbol atau tanda makna pesan dalam film Susah Sinyal. 
Millenia Vega Wong, Daniel Tamburian: Analisis Semiotika Representasi Ibu Tunggal dalam Film Susah Sinyal

\section{Metode Penelitian}

Penelitian ini menggunakan metode semiotika untuk menganalisis makna atau pesan yang tersurat di balik teks (verbal) maupun non verbal yang ada pada film Susah Sinyal (Han, 2018:244). Teori-teori dari semiotika ini berhubungan dengan karya Rolland Barthes.

Semiotika adalah ilmu yang mempelajari tentang luasnya objek, kejadian, dan sebagai sebuah symbol (Eco, dalam Sobur 2006: 95). Menurut Rolland Barthes, semiotika berfokus pada bagaimana menyampaikan ideologi yang tersirat dari suatu bahasa. Rolland membaginya dalam 3 hal yakni: denotasi, konotasi dan ideologi. Denotasi merupakan hal pertama yang dijelaskan sebagai penanda dan petanda pada kenyataan yang membuahkan makna eksplisit, jelas dan pasti. Konotasi merupakan tingkatan diatas denotasi yang menjelaskan tentang penanda dan petanda yang membuahkan makna implisit, tidak jelas dan tidak pasti (Kusumarini, 2006).

Peneliti mengumpulkan data melalui observasi dan pengamatan dengan menonton film Susah Sinyal. Melalui pengamatan, peneliti mengidentifikasi sejumlah scene yang berisi simbol atau tanda yang merepresentasi ibu tunggal dalam Film Susah Sinyal. Pemaknaan tersebut akan diinterpretasikan penulis melalui analisis semiotika.

Data primer yang digunakan oleh peneliti yaitu mengidentifikasi sejumlah scene yang ada di Film Susah Sinyal, mengumpulkan dan menemukan data dengan metode Analisis Semiotika karya Rolland Barthes. Rolland Barthes dikenal sebagai seorang ahli konstruksi yang menerapkan model linguistik dan semiologi Saussure. Rolland Barthes berpendapat bahwa bahasa merupakan suatu simbol yang menginterpretasikan asumsi-asumsi dari suatu masyarakat dalam waktu tertentu (Sobur, 2013:63).

Menurut Rolland Barthes, semiotika berfokus pada bagaimana menyampaikan ideologi yang tersirat dari suatu bahasa. Rolland membaginya dalam 3 hal yakni: denotasi, konotasi dan ideologi. Peneliti melakukan observasi dengan menonton film Susah Sinyal. Peneliti mengidentifikasi beberapa scene yang berhubungan dengan representasi ibu tunggal yang digambarkan oleh tokoh Ellen dan simbol, tanda atau makna yang ada pada scene tersebut. Data sekunder yang dilakukan dalam penelitian ini yaitu berupa dokumen film, jurnal, artikel yang kredibel, serta buku-buku yang relevan dalam melakukan penelitian ini.

Muhadjir mengemukakan analisis data adalah usaha mencari dan membenahi secara sistematis hasil catatan observasi, wawancara dan lainnya untuk meningkatkan kognisi penulis tentang penelitian yang diteliti dan menyuguhkan sebagai penemuan bagi orang lain (Rijali, 2018). Dari pengertian itu, terkandung beberapa hal yang harus ditekankan, yaitu: a) perlunya proses lapangan untuk mencari data dengan berbagai persiapan pralapangan; b) membenahi hasil temuan di lapangan secara analitis; c) menyediakan temuan di lapangan; d) mencari arti, pencarian arti terus menerus hingga tidak ada lagi arti yang menyembunyikannya, perlunya pengembangan wawasan bagi peneliti terhadap masalah yang terjadi.

\section{Hasil Temuan dan Diskusi}

Pada bagian ini, peneliti akan memaparkan temuan pada sejumlah scene yang berhubungan dengan representasi ibu tunggal dalam Film Susah Sinyal: 


\begin{tabular}{|c|c|}
\hline Dialog/suara & Visual \\
\hline $\begin{array}{l}\text { Iwan: Udah mau resign, masih aja } \\
\text { nginep. } \\
\text { Ellen: Ini kan file-file harus gua beresin, } \\
\text { masa harus ngurusin diri sendiri filenya, } \\
\text { kan gak. } \\
\text { Iwan: gua bisa kali bantuin lo, lo aja yang } \\
\text { males pulang. }\end{array}$ & $\begin{array}{l}\text { Ellen sedang membereskan barangnya } \\
\text { dikantor dan Iwan yang menghampiri } \\
\text { Ellen }\end{array}$ \\
\hline Signifier dan Signified Denotative & Connotative Signifier \\
\hline $\begin{array}{l}\text { Seorang perempuan yang mengenakan } \\
\text { kaos biru sedang membereskan barang- } \\
\text { barangnya diruangannya dan kemudian } \\
\text { seorang laki-laki dengan pakaian rapi } \\
\text { mengenakan kemeja putih, dasi abu-abu } \\
\text { dan dibaluti jas abu-abu duduk sambil } \\
\text { memegang selimut yang ada di sofa } \\
\text { tersebut. }\end{array}$ & $\begin{array}{l}\text { Walaupun sudah mau resign, Ellen } \\
\text { merasa masih bertanggung jawab } \\
\text { penuh atas berkas-berkas dan file yang } \\
\text { ada di kantor, sehingga ia memutuskan } \\
\text { untuk menginap. }\end{array}$ \\
\hline \multicolumn{2}{|c|}{ Connotative Signified } \\
\hline $\begin{array}{l}\text { Ucapan Iwan kepada Ellen menunjukkar } \\
\text { kantor dan jarang pulang kerumah } \\
\text { menghabiskan waktu dirumah. Ellen yang } \\
\text { dan merepresentasikan seorang ibu tungga }\end{array}$ & $\begin{array}{l}\text { bahwa Ellen sering kali menginap di } \\
\text { dengan begitu Ellen sangat jarang } \\
\text { sibuk dikantor mengurusi pekerjaannya } \\
\text { yang pekerja keras dan Independent. }\end{array}$ \\
\hline
\end{tabular}

Mitosnya adalah biasanya masyarakat menganggap bahwa seorang ibu tunggal akan lebih sering dirumah dan menghabiskan waktu bersama anak tetapi lain hal dengan tokoh Ellen yang malah lebih sering menghabiskan waktu di kantor dan jarang dirumah. Ellen yang begitu mencintai pekerjaannya dan merasa tanggung jawab atas pekerjaannya sepenuhnya ada di tangannya.

\begin{tabular}{|l|}
\hline \multicolumn{1}{|c|}{ Dialog/suara } \\
\hline Iwan: Ribet yah, pantesan lo malas \\
kawin lagi yah \\
Ellen: Heh! Bukan karna itu juga kali \\
Iwan: Karena apa? \\
Ellen: Karena semua laki-laki itu \\
brengsek \\
Iwan: Termasuk Aji? \\
Ellen: Yah... gua gak tau lah \\
Iwan: Nah, lo gak tau kan? Kok nuduh? \\
Siapa tau dia baik?
\end{tabular}




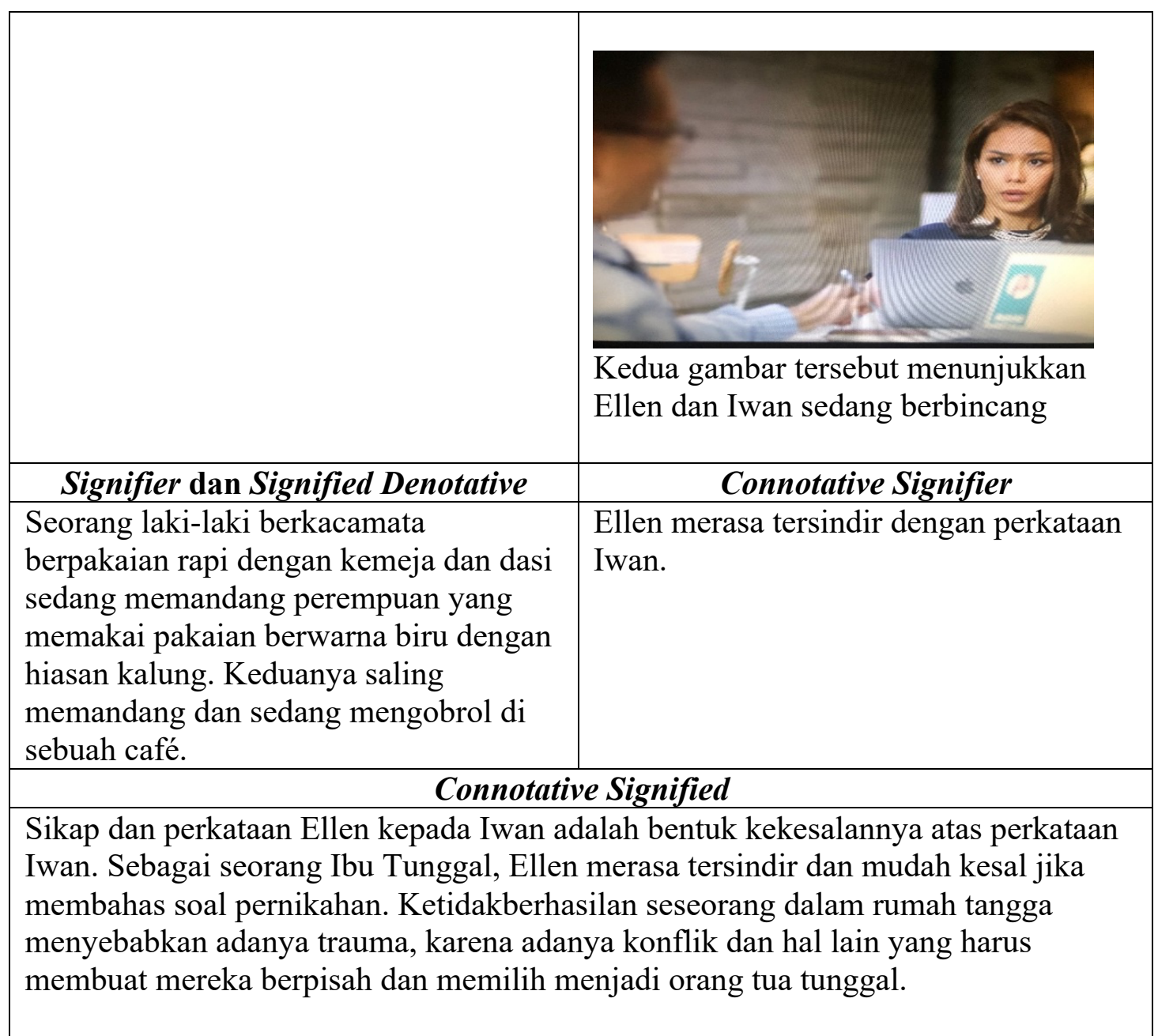

Mitosnya Ellen merupakan seorang ibu tunggal yang emosional. Ellen dengan mudahnya mengekspresikan atau meluapkan emosinya yang sedang ia rasakan. Tak heran jika perempuan dianggap individu yang sentimental, sensitif dan mudah tersinggung.

\section{Tinjauan Umum Film}

Menurut Oktavianus (2015:3), film adalah suatu gambaran media audio visual dalam komunikasi massa yang dapat menampilkan kata-kata, suara, citra, dan gabungannya. Menurut McQuail film berperan sebagai sarana hiburan yang menjadi kebiasaan sebelumnya, serta menyajikan cerita, lawakan, musik, drama untuk masyarakat (Oktavianus, 2015:3). Romli menyatakan bahwa salah satu media komunikasi massa yang saat ini sedang marak adalah film. Jalan cerita yang mengagumkan serta impresi suara yang baik adalah salah satu alasan masyarakat tidak jenuh saat menikmatinya dan tidak perlu berkhayal seperti membaca buku (Angela dan Winduwati, 2019:479).

Ini berkaitan dengan Film Susah Sinyal yang bergenre drama komedi yang disutradarai oleh Ernest Prakasa. Pembuatan naskah film ini, Ernest Prakasa dibantu oleh sang istri, Meira Anastasia. Sebagai sutradara dan juga penulis naskah, Ernest membentuk hubungan dengan sejumlah karakter pemain tersusun lewat adegan yang diatur secara detail. Walaupun lokasi, waktu, dan tokoh-tokoh di dalam film ini berbeda-beda, tetapi adegan demi adegan saling berkaitan satu sama lain. Film Susah 
Sinyal juga menggunakan lokasi yang banyak dan komposisi dan struktur atau rancangan antara drama konflik dan penghibur seperti komedi juga tidak terasa aneh atau berat sebelah. Adanya unsur komedi yang ada pada film ini juga sangat didukung dengan pemain yang memang notabenenya adalah seorang comedian sehingga ekspresi, gerakan, lawakan dan juga cara mereka berdialog pun memang sangat menghibur penonton. Film Susah Sinyal juga memperkenalkan keindahan pemandangan, pantai dan suasana yang ada di Sumba. Pemilihan tempat dengan mengangkat kehidupan orang Sumba juga menambah apiknya film ini.

\section{Representasi}

Menurut Danesi, representasi didefinisikan sebagai simbol yang menghubungkan, memvisualisasikan, pengambil gambar, dan menciptakan sesuatu yang dapat dilihat, dibayangkan, dan dirasakan dalam bentuk wujud (Putra, 2019). Representasi ibu tunggal dalam Film Susah Sinyal ini memperlihatkan kepada penonton atau masyarakat seorang ibu tunggal yang mandiri, pekerja keras, emosional, sangat bertanggung jawab dengan apa yang dikerjakannya, dan optimis dengan kemampuannya. Sebagai seorang ibu, Ellen juga cukup tegas dengan anaknya dan mempunyai sifat pengontrol.

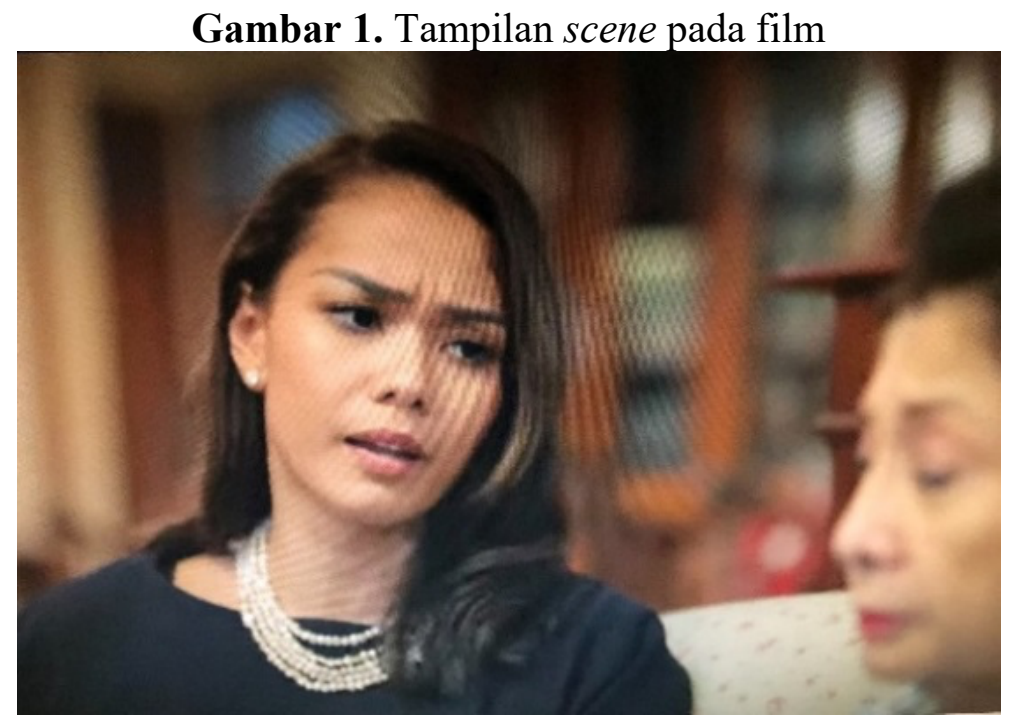

Sumber: Dokumentasi pribadi dari situs Netflix.com

Mengambil dari salah satu scene yang merepresentasikan ibu tunggal, adegan ini diambil secara close up untuk menunjukkan mimik wajah yang jelas dan suasana pada adegan tersebut.

\section{Teori Semiotika Roland Barthes}

Menurut Roland Barthes, semiotika berfokus pada bagaimana menyampaikan ideologi yang tersirat dari suatu bahasa. Roland membaginya dalam 3 hal yakni: denotasi, konotasi dan ideologi. Denotasi merupakan hal pertama yang dijelaskan sebagai penanda dan petanda pada kenyataan yang membuahkan makna eksplisit, jelas dan pasti. Konotasi merupakan tingkatan diatas denotasi yang menjelaskan tentang penanda dan petanda yang membuahkan makna implisit, tidak jelas dan tidak pasti (Kusumarini, 2006). Hasil dari denotasi dan konotasi pada sejumlah scene yang merepresentasikan ibu tunggal dalam Film Susah Sinyal ini dapat disimpulkan 
bahwa ibu tunggal yang diperankan oleh Ellen adalah seorang ibu tunggal yang pekerja keras, optimis dan yakin dengan kemampuannya sebagai pengacara. Ellen juga sering menginap di kantor sehingga jarang pulang kerumah, itu mengapa Ellen jarang berkomunikasi dengan Kiara, anaknya. Walaupun begitu, Ellen tetap bertanggung jawab dengan segala perbuatan dan perilaku Kiara. Tetapi Ellen juga tidak semata-mata memanjakan Kiara, Ellen juga cukup tegas kepada Kiara dan memperingati Kiara bahwa setiap omongan mereka adalah janji. Di samping itu, Ellen juga cukup emosional dalam menghadapi suatu masalah yang ada.

\section{Simpulan}

Ibu tunggal yang direpresentasikan oleh Ellen dalam Film Susah Sinyal adalah seorang ibu tunggal yang mempunyai karakter tegas dan emosional. Di samping itu, Ellen juga adalah perempuan yang mandiri, pekerja keras, sangat bertanggung jawab dengan apa yang dikerjakannya, dan optimis dengan kemampuannya. Ellen sebagai ibu tunggal sangat mencintai pekerjaannya lebih sering menghabiskan waktunya di kantor sebagai pengacara dari pada di rumah. Walaupun begitu, Ellen juga masih menunjukkan tanggung jawabnya atas perbuatan yang dilakukan oleh anaknya. Sebagai seorang ibu tunggal, Ellen juga menunjukkan perannya sebagai seorang ibu yang cukup tegas dengan anaknya dan mempunyai sifat pengontrol dalam menerapkan beberapa aturan yang harus dipatuhi tanpa terkecuali dengan tujuan agar anak tetap dapat terkontrol. Ketika ada masalah yang terjadi di antara Ellen dan anaknya, Ellen juga seorang ibu tunggal yang memilih untuk segera menyelesaikan dan memperbaikinya. Selain itu, ketidakberhasilan Ellen dalam rumah tangga menyebabkan adanya trauma, karena adanya konflik dan hal lain yang harus membuat mereka berpisah dan memilih menjadi orang tua tunggal. Hal itulah yang membuat Ellen beranggapan bahwa semua laki-laki itu tidak baik.

\section{Ucapan Terima Kasih}

Pada kesempatan ini, penulis ingin mengucapkan terima kasih kepada Dekan, Wakil Dekan, Kaprodi Fakultas Ilmu Komunikasi Universitas Tarumanagara dan dosen pembimbing yang telah membantu dan membimbing penulis dalam menyelesaikan penelitian. Penulis juga berterima kasih kepada pacar, sahabat dan teman-teman seperjuangan lainnya yang telah memberikan masukan dan dukungan dalam pembuatan penelitian.

\section{Daftar Pustaka}

Angela, Michelle dan Septia Winduwati. (2019). Representasi Kemiskinan dalam Film Korea Selatan (Analisis Semiotika Model Saussure pada Film Parasite). Jurnal Koneksi. 3(2). 478-484.

Asdir, Astifah. (2015). Memahami Pola Komunikasi Single Mother Terhadap Perkembangan Konsep Diri Anak Perempuan. Skripsi. Semarang: Ilmu Sosial dan Ilmu Politik. Universitas Diponegoro Semarang.

Dewi, Listia. (2017). Kehidupan Keluarga Single Mother. Jurnal Bimbingan dan Konseling. 2(3). 44-48.

Han, Muhammad Ibtissam. (2018). Representasi Konflik Ibu Tunggal dan Anak dalam Film Susah Sinyal. Jurnal Dakwah dan Komunikasi. 12(2). 241-256. 
Kusumarini, Yusita. (2006). Teori Semiotic. Surabaya: Universitas Kristen Petra.

Oktavianus, Handi. (2015). Penerimaan Penonton Terhadap Praktek Eksorsis di dalam Film Conjuring. Jurnal E-Komunikasi. 3(2). 1-12.

Putra, Muhammad Faisal Wisnu Ananta. (2019). Representasi Single Parent dalam Film Susah Sinyal. Jurnal Komunikasi. 7(2). 197-208.

Rahayu,Afina Septi. (2017). Kehidupan Sosial Ekonomi Single Mother dalam Ranah Domestik dan Publik. Jurnal Analisa Sosiologi. 6(1). 82-99.

Rijali, Ahmad. (2018). Analisis Data Kualitatif. Jurnal Alhadharah. 17(33). 81-9.

Sobur, Alex. (2013). Semiotika Komunikasi. Bandung: PT. Remaja Rosdakarya. 